\title{
BIOCOMBUSTÍVEL: UMA QUESTÃO DE SUSTENTABILIDADE
}

\section{Kevin Christian de Melo Bacochina ${ }^{1}$ \\ Leonardo Henrique Coelho da Silva² \\ Valquiria Tereza Valério Martins ${ }^{3}$ \\ Helder Faria ${ }^{4}$}

Resumo: $O$ artigo refere-se a uma atividade de pesquisa e experimentação realizada no primeiro semestre de 2016 por uma equipe de alunos da escola E.E.E.I. Professor Nelson do Nascimento Monteiro durante as aulas semanais da Disciplina Eletiva "Caminhos da Ciência". Essa disciplina da escola integral é escolhida pelos alunos conforme a profissão que querem seguir, podendo elaborar pesquisas e projetos conforme sua escolha profissional com o auxílio de professores de áreas específicas. Este artigo tem como objetivo estudar, aprofundar e compreender o uso do biocombustível, buscando a inovação na técnica da síntese e seus benefícios para a sustentabilidade tendo como base o estudo da química orgânica voltada para as reações orgânicas, estudo de compostos orgânicos, suas propriedades e utilidades no dia a dia. Palavras-chave: Biocombustível; Inovação; Sustentabilidade; Compreensão; Química.

\footnotetext{
${ }^{1}$ E.E.E.I Professor Nelson do Nascimento Monteiro, Brasil. E-mail: valquiriatvm@gmail.com.

2 E.E.E.I Professor Nelson do Nascimento Monteiro, Brasil. E-mail: e042328@see.sp.gov.br.

${ }^{3}$ E.E.E.I Professor Nelson do Nascimento Monteiro, Brasil. E-mail: Ivtv@ig.com.br.

${ }^{4}$ E.E.E.I Professor Nelson do Nascimento Monteiro, Brasil. E-mail: profheder@ig.com.br.
} 